\title{
POTENCIALIDADES NO USO DO SISTEMA DE CLICKERS VOTOINO NA PROMOÇÃO DA AVALIAÇÃO FORMATIVA EM AULAS DE QUÍMICA NO ENSINO BÁSICO
}

\author{
POTENTIAL USE OF THE VOTOINO CLASSROOM RESPONSE SYSTEM TO PROMOTE \\ FORMATIVE ASSESSMENT IN CHEMISTRY CLASSES IN BASIC EDUCATION \\ POTENCIALIDADES EN EL USO DEL SISTEMA CLICKER VOTOINO QUE PROMUEVE \\ LA EVALUACIÓN FORMATIVA EN LAS CLASES DE QUÍMICA EN LA ESCUELA \\ SECUNDARIA
}

Joyce Ingrid de Lima

E-mail: joyce.limaa@hotmail.com Maria Inês Marques de Souza E-mail: maria.souza@aluno.ifsp.edu.b Afonso Celso Turcato E-mail: afonso.turcato@,ifsp.edu.br Francisco de Araújo Silva

E-mail: francisco@,ifsp.edu.br Instituto Federal de Educação, Ciência e Tecnologia de São Paulo (IFSP) Campus Sertãozinho - SP

\section{RESUMO}

O uso de metodologias de ensino com a inserção de novas tecnologias vem aumentando nas últimas décadas, com o advento e o acesso às tecnologias da informação e comunicação. Em algumas estratégias, estas ferramentas têm auxiliado na prática da avaliação formativa. Neste trabalho, apresentamos a evolução do Votoino - um clicker para votação eletrônica em sala de aula - e sua aplicação em uma sequência didática sobre o tema termoquímica em uma turma de $2^{\circ}$ ano do ensino técnico em automação integrado ao ensino médio. O aprimoramento do Votoino para a sala de aula, como um dispositivo simples que não necessita do acesso à internet ou um celular, mostrou-se bastante promissor na avaliação formativa da turma: os resultados obtidos de forma imediata, o anonimato dos alunos nas respostas, a possibilidade de interação do aluno com o professor e com a turma através do painel de votação, dentre outros aspectos importantes, trouxeram novos direcionamentos no replanejamento das aulas futuras. O uso de uma sequência didática adequada, mediada por exposições curtas do professor e monitorada pelos resultados dos exercícios obtidos com o Votoino, foi inspirado na metodologia Peer Instruction (Instrução por pares) e trouxeram resultados e impactos positivos, bem como reflexões sobre o verdadeiro papel da avaliação na sala de aula

PALAVRAS-CHAVE: Instrução por pares. Votoino. Avaliação formativa.

\section{ABSTRACT}

The use of teaching methodologies applying new technologies has been increasing in recent decades, especially with the advent and easier access to new information and communication technologies. These tools have helped in the practice of formative assessment in some strategies. In this work, we present the improvement of the Votoino - a classroom response system - and its application in a didactic sequence on thermochemistry in a 2 nd year high school class integrated to technical studies in automation. The improvement of the Votoino for the classroom, as a simple device, without the need for internet or cell phone, proved to be very promising in the formative assessment of the class. Real time results, anonymity, possible interactions with the professor and the other students through the voting panel, among other important aspects, brought new directions in the re-planning of 
future classes. The use of an appropriate didactic sequence, mediated by a short talk of the teacher, monitored by the results of the exercises obtained with the Votoino, was inspired by the Peer Instruction methodology and brought positive results and impacts, as well as reflections on the true role of evaluation inside the classroom.

KEYWORDS: Peer Instruction. Votoino. Formative assessment.

\section{RESUMEN}

El uso de metodologías de enseñanza utilizando nuevas tecnologías ha aumentado en las últimas décadas con el advenimiento y el acceso a las tecnologías de la información y la comunicación. En algunas estrategias, estas herramientas han ayudado en la práctica de la evaluación formativa. En este trabajo presentamos la mejora de Votoino - el clicker de voto electrónico en el aula - y su aplicación en una secuencia didactica sobre el tema termoquímica en una clase de $2^{\circ}$ año de la tecnicatura en automatización integrada a la escuela secundaria. La mejora de Votoino para el aula se mostró efectiva en la evaluación formativa de la clase: es un dispositivo simple sin necesidad de internet o smartphone, los resultados obtenidos instantaneamente, el anonimato de los estudiantes en las respuestas, la posibilidad de interacción del alumno con el maestro y la clase a través del panel de votación, entre otros aspectos importantes, trajeron nuevas direcciones para replaneamento de las clases futuras. El uso de una secuencia didactica apropiada mediada por exposiciones cortas del maestro y monitoreado por los resultados de los ejercicios obtenidos con Votoino se inspiró en la metodología Peer Instruction (Instrucción entre pares) y trajo resultados e impactos positivos, así como reflexiones sobre el verdadero papel de la evaluación en el aula.

PALABRAS-CLAVE: Instrucción entre pares. Votoino. Evaluación formativa.

\section{INTRODUÇÃO}

Ensinar conceitos abstratos é um dos desafios para os professores do ensino de ciências exatas, pois, devido não ser algo palpável, os alunos apresentam bastante dificuldade, sendo esse um dos principais motivos de desinteresse na sala de aula. Esta dificuldade pode ter origem no formato tradicional das aulas, uma vez que o professor faz uso contínuo de aulas descritas como expositiva e "dialogada", diálogo que muitas vezes se trata de um monólogo longo do professor, dificultando ainda mais a compreensão e o processo de aprendizagem. No chamado 'ensino tradicional', o conhecimento é reduzido a memorização do conteúdo com a maioria dos alunos estudando as vésperas das provas, quando o fazem, e cujo único objetivo tem sido uma nota satisfatória nestes exames. O desinteresse nas aulas pode levar a outros problemas que tem dificultado o trabalho docente como a indisciplina na sala de aula, uma vez que, ao não acompanhar o conteúdo, o aluno tende a praticar atividades paralelas como o uso do celular ou a conversa com os demais colegas (COSTA; PASSERINO; ZARO, 2012; MORAN, 2012).

Atualmente, percebe-se que o ensino tradicional ainda é muito utilizado no ensino de ciências, mesmo pesquisas apontando a pouca eficiência para o aprendizado dos alunos. Nesse contexto, novas metodologias de ensino vêm ganhando atenção para melhorar o desenvolvimento dos alunos ao empregar, dentre outras atividades, o uso de trabalhos em grupos e/ou o uso de novas tecnologias da informática (RIBEIRO; RAMOS, 2012). 


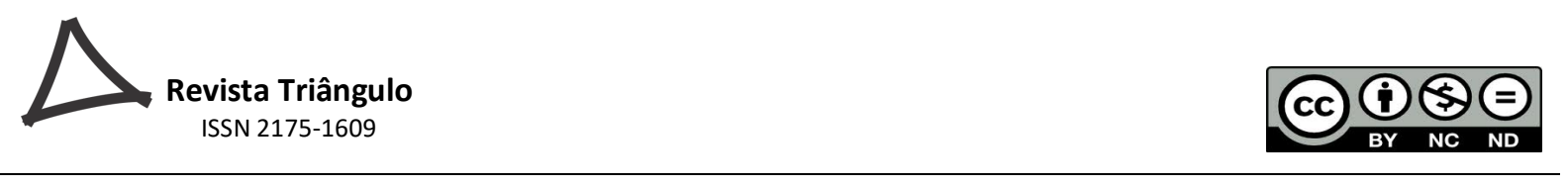

Com isso, diversas estratégias de ensino têm sido discutidas, chamadas de 'novas metodologias de ensino', com o objetivo de aprimorar o processo de ensino-aprendizagem e a produção de conhecimento. O uso destas novas estratégias de ensino atreladas ao uso de TICs (Tecnologias da Informação e Comunicação) possibilita uma interação mais efetiva em sala de aula, atribuindo o papel de mediador da aprendizagem ao professor, e um papel mais ativo aos alunos. Estas tecnologias caracterizam-se pela rápida evolução e transformação, por serem imateriais, ocupando espaço e ação de forma virtual, e cuja principal matéria-prima é a informação. Desta forma, tendo em vista a influência destas tecnologias na sociedade atual, não cabe mais à escola e aos professores o distanciamento das mesmas (GAYDECZKA; KARWOSKI, 2015; KENSKI, 2012).

Dentre as novas metodologias de ensino podemos encontrar alguns trabalhos na literatura que tratam destes temas. Para citar alguns exemplos: Team-Based Learning (TBL) ou Aprendizagem Baseada em Equipes (OLIVEIRA; ARAUJO; VEIT, 2016); Problem-Based Learning (PBL) ou Aprendizagem Baseada em Problemas (ASSUMPÇÃO; SOARES, 2017), ou ainda o Project-Based Learning ou Aprendizagem Baseada em Projetos (PASQUALETTO; VEIT; ARAUJO, 2017); a gamificação em aulas (SILVA LEITE, 2018); o Think Pair Share (REIS; BARRETO, 2017) e o Peer Instruction, ou Instrução por pares/colegas (ARAUJO; MAZUR, 2013).

Dentre essas metodologias, destacou-se para nós a estratégia Peer Instruction (PI), ou Instrução por Pares, ou Instrução pelos Colegas, como vários trabalhos nacionais têm traduzido. A metodologia ativa Peer Instruction vem ganhando espaço nas escolas ao redor do mundo, bem como no Brasil, nos últimos anos. Esta metodologia foi criada pelo Professor Erick Mazur, na década de 1990, em aulas de física na Universidade de Harvard. Em resumo, o professor explica determinado conceito ou conteúdo em um tempo curto, de aproximadamente quinze minutos, e realiza um teste conceitual (TC) de múltipla escolha, no qual os alunos devem responder em cerca de dois minutos, de forma individual. Na sequência o professor analisa a resposta: se a maior parte dos alunos votar corretamente (pelo menos 70\%), o professor entende que houve uma boa compreensão do conceito explicado, logo resolve rapidamente a questão e passa para o próximo teste. Se a menor parte dos alunos votar corretamente (abaixo de 30\%), o professor discute novamente o assunto, e outro teste similar será realizado. Caso o número de acertos na votação fique entre $30 \%$ e $70 \%$, os alunos são instruídos a formar grupos para discutir o teste e o mesmo é realizado novamente (essa discussão em grupo com os seus pares torna a 
estratégia de ensino ativa). Depois de analisar as respostas dos TCs, o professor também promove uma discussão para saber o porquê das respostas dos alunos, incentivando-os a tirarem dúvidas sobre os testes. Com algumas particularidades, diversos trabalhos na literatura nacional trazem mais informações sobre a metodologia PI (ARAUJO et al., 2017; ARAUJO; MAZUR, 2013; KARWOSKI, 2013; MÜLLER et al., 2017; TEIXEIRA; FONTENELE, 2017). A figura 1 resume a descrição da metodologia PI.

Figura 1. Diagrama com a representação da aplicação do método PI.

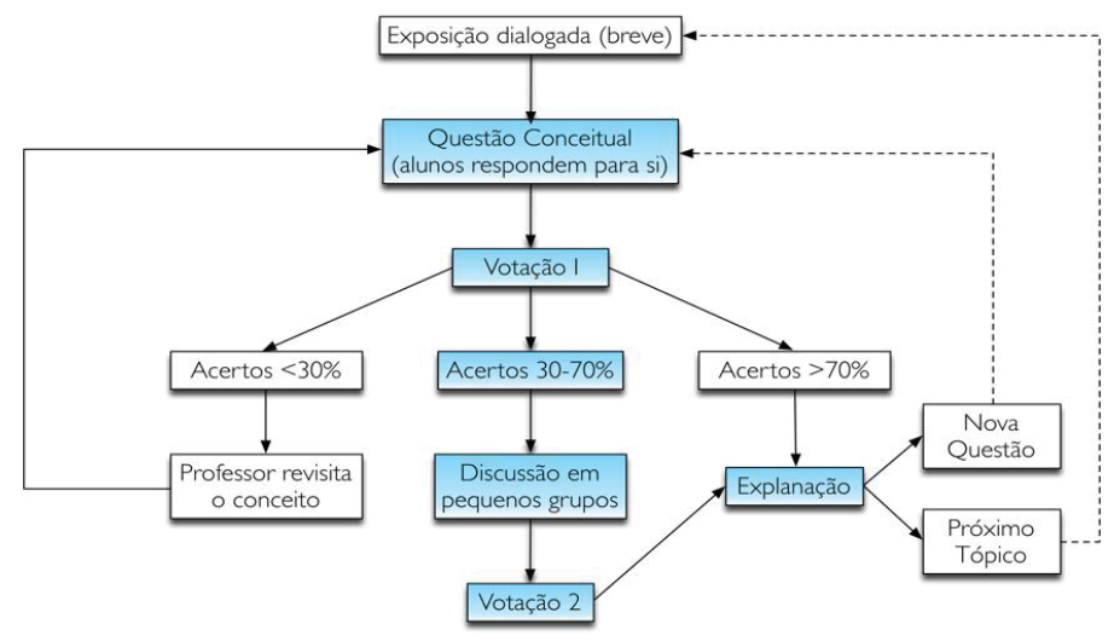

Fonte: (ARAUJO; MAZUR, 2013).

O tópico que primeiramente nos chama a atenção nesta metodologia está atrelado ao tema avaliação, que acontece nos momentos de votação dos TCs. Acreditamos que a avaliação não tem sido empregada de forma adequada nas escolas de um modo geral. Percebe-se, a partir de nossa prática cotidiana, uma defasagem na formação inicial e continuada dos professores sobre este tema, fazendo com que a avaliação se torne uma atividade pontual ao final dos períodos letivos, sem significado dentro do planejamento do processo de ensino-aprendizagem. Por este motivo, a metodologia PI nos alertou sobre a importância do uso da avalição formativa na sala de aula, pautada em objetivos claros e necessidade de novos caminhos a partir dos resultados.

A avaliação deve subsidiar decisões sobre a nossa prática pedagógica, nos direcionando nas análises sobre os resultados que deveriam ser alcançados, propiciando reflexões para o (re)planejamento de nossas estratégias e trilhas de construção da aprendizagem dos alunos. Fazse necessário o uso da avaliação formativa, contínua e intensiva proposta por Perrenoud (1999), 
de maneira que o docente possa, de fato, acompanhar os resultados de sua prática, objetivo que de modo geral não tem sido alcançado com avaliações convencionais ao final de bimestres e/ou semestres letivos (LUCKESI, 2011; PERRENOUD, 1999).

Ao analisarmos a estratégia de avaliação na metodologia PI, identificamos dois pontos cruciais para o melhor funcionamento e aproveitamento: a escolha dos testes conceituais adequados e a forma como serão coletados os votos dos alunos, sem que a dinâmica da aula seja comprometida. Os testes conceituais têm um importante papel na aula pois devem estar claramente conectados com os objetivos da sequência didática, versando sobre os conceitos centrais da exposição do professor. Estes testes devem ser desafiadores e podem ser elaborados ou selecionados atendendo níveis adequados e escalonados na dificuldade da resolução, podem ser trabalhados também na forma de questões isomórficas. Vários trabalhos na literatura nacional usam os exercícios de vestibulares ou o Exame Nacional do Ensino Médio (ENEM) como fontes para estes testes, bem como discutem este tópico (ARAUJO et al., 2017; KIELT; DA SILVA; MIQUELIN, 2017; MÜLLER et al., 2017).

Sobre a forma de coleta dos votos dos alunos alguns trabalhos nacionais descrevem o uso de diversas ferramentas: plataformas, aplicativos e softwares como Google Docs (BARBERIA et al., 2014; LIMA; SANTOS, 2016; MÜLLER et al., 2012), Moodle (OLIVEIRA, 2017; OLIVEIRA et al., 2017), Socrative (DIESEL et al., 2017; DIESEL; FORNECK; MARTINS, 2016; RIBEIRO et al., 2016), Picklers (ARAUJO et al., 2017), etc.; flashcards (CAMPAGNOLO et al., 2014; MÜLLER; ARAUJO; VEIT, 2017; OLIVEIRA; VEIT; ARAUJO, 2015; TEIXEIRA; FONTENELE, 2017; ZANATTA et al., 2017); controles remotos como o iclicker, etc. (DUMONT; CARVALHO; NEVES, 2016). Os trabalhos de Kielt e colaboradores, bem como o de Medeiros \& Bessa apresentaram aplicativos originais (KIELT; DA SILVA; MIQUELIN, 2017; MEDEIROS; BESSA, 2017). Utilizar a tecnologia como recurso educacional para aquisição das respostas destes testes auxilia muito o professor, pois se economiza tempo, promove uma boa aceitação dos alunos e um melhor aproveitamento da aula (DUMONT; CARVALHO; NEVES, 2016; MEDEIROS; BESSA, 2017).

É importante ressaltarmos que essas votações não implicam em dar notas, mas têm papel fundamental na avaliação formativa dos alunos, seja de forma individual (caso se utilize um dispositivo capaz de monitorar o desempenho do estudante), ou coletiva, de modo que o voto do aluno não precisa ser identificado e o resultado final da votação é apresentado de forma genérica da turma como um todo. Esta ideia pode melhorar a participação dos alunos que 
geralmente têm receio de se expor na sala de aula, bem como mostrar para o docente se o formato da aula, a estratégia usada, a explicação, etc, está sendo efetiva para aprendizagem do conceito explanado.

Cada um dos trabalhos que descrevem o uso de diferentes ferramentas para coleta de votos dos alunos aponta vantagens e desvantagens dos recursos adotados. A partir destas observações, trabalhamos na produção de um sistema de votação similar ao clicker, que chamamos de Votoino. Desta forma, neste trabalho apresentaremos os resultados da segunda versão deste dispositivo, resultado do aprimoramento das aplicações da primeira versão descrito em trabalho anterior (LIMA; TURCATO; SILVA, 2020). Embora este dispositivo seja inspirado na metodologia PI, sua aplicação pode ser feita de forma geral na sala de aula para a avaliação formativa dos alunos, bem como seu software pode ser adaptado de forma relativamente viável para diversas ideias e realidades determinadas nos diferentes contextos e níveis de ensino. Os resultados aqui apresentados estão voltados a análise do funcionamento desta segunda versão do dispositivo, aplicado em uma sequência didática de uma aula de química, no intuito de verificar se o Votoino é capaz de auxiliar o professor no replanejamento de sua prática, durante e depois da aula, com base na possível avaliação formativa proporcionada.

\section{MÉTODOS}

O dispositivo eletrônico de votação (ou clicker), que chamamos de Votoino, produzido no Instituto Federal de Educação, Ciência e Tecnologia de São Paulo (IFSP), campus Sertãozinho está em sua segunda versão. A primeira versão do Votoino (apresentada no artigo LIMA; TURCATO; SILVA, 2020) foi constituída por 40 controles remotos por rádio frequência com apenas dois botões - adquiridos comercialmente como controles de portão eletrônico - e uma central receptora constituída por uma placa de Arduino Nano Rev.3 e um módulo receptor RF como plataforma de hardware (figura 2.1), que faz a interface com o software - um painel de acompanhamento da votação dos alunos (figura 2.2) e um painel de resultados ao final de cada votação (figura 2.3) que roda em sistema operacional Windows. Esta primeira versão do Votoino só era utilizada pelo professor em questões que permitissem apenas duas respostas distintas. 
Figura 2. (1) Controles usados no primeiro protótipo do Votoino; (2) Painel que mostra em tempo real a participação do aluno (não identifica o aluno para que o mesmo participe espontaneamente); (3) Painel de resultado que pode ser apresentado a critério do professor
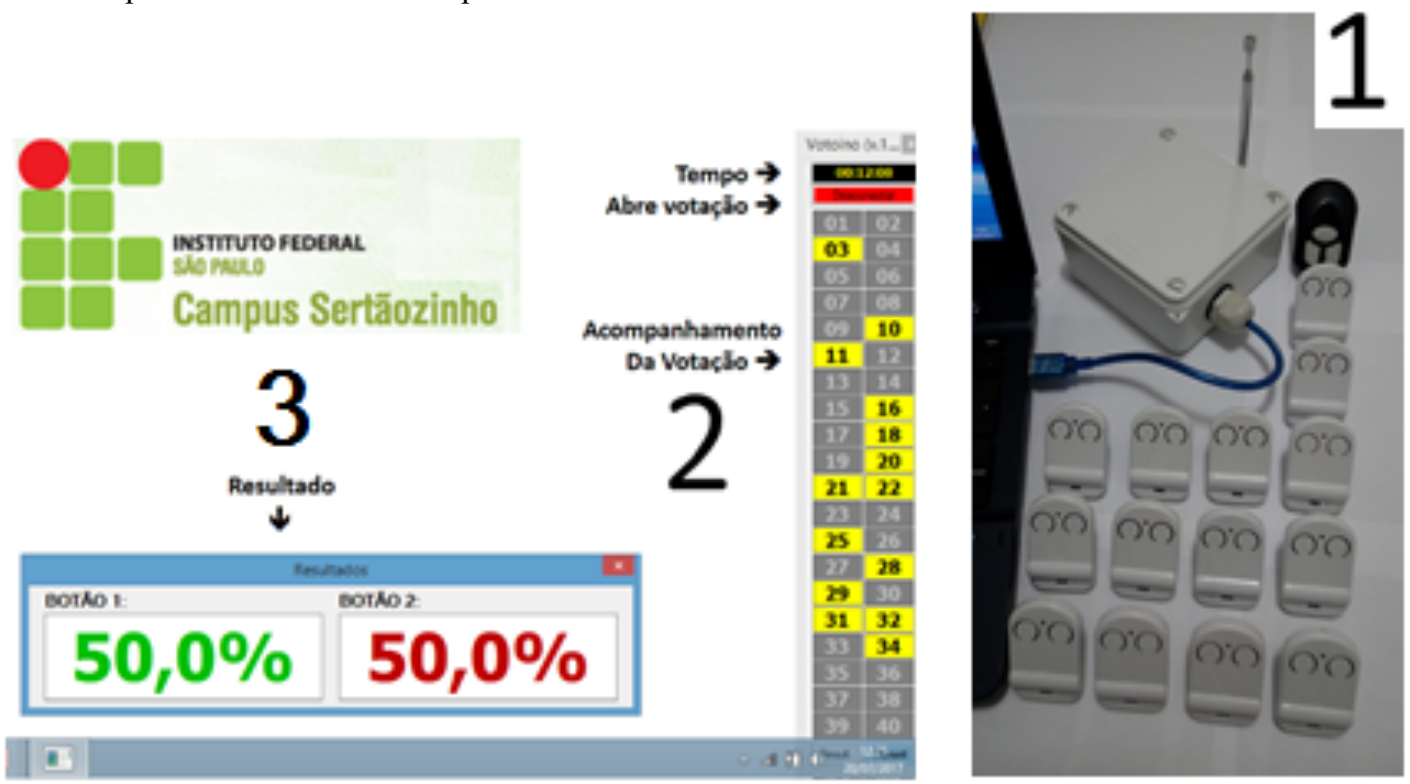

Fonte: adaptado de LIMA; TURCATO; SILVA, 2020.

$\mathrm{Na}$ segunda versão do Votoino que apresentamos aqui ocorreram mudanças significativas: os controles remotos (ainda adquiridos comercialmente - há projeção para a produção das placas destes controles no próprio IFSP) passaram a ter 6 botões (figura 3.1); a central receptora de Arduino foi encapsulada em recipiente mais adequado produzido em impressora 3D (também no IFSP-Sertãozinho) facilitando o armazenamento e trazendo praticidade na conexão via cabo USB ao computador do professor; a recepção de sinal também melhorou, diminuindo a interferência durante a votação dos alunos, que é detectado pelo painel de votação da figura 3.2; e o painel de visualização dos resultados, figura 3.3, que mostra a quantidade de alunos que apertaram cada botão (ou escolheram cada alternativa do exercício / TC), na forma de gráfico de barras com porcentagens, além de outros gráficos como o de tempo de resposta por controle remoto. $\mathrm{O}$ controle remoto com 6 botões permite que o professor tenha o feedback dos alunos em questões de múltipla escolha com alternativas A, B, C, D e E, correlacionados aos botões de 1 a 5 . O botão 6 é usado como uma abstenção do exercício ou teste conceitual, para que o aluno não 'chute' a resposta, permitindo a participação de todos os alunos de forma anônima, inclusive permitindo ao aluno que não consegue resolver o exercício que se expresse através do controle de forma adequada, auxiliando assim o professor na análise mais minuciosa dos resultados. 
Figura 3. (1) Controles de 6 botões usados na segunda versão do Votoino e capsula contendo Arduino para recepção de sinal; (2) Painel que mostra em tempo real a participação do aluno (não identifica o aluno para que o mesmo participe espontaneamente); (3) Painel de resultado que pode ser apresentado por projeção pelo professor após a votação.
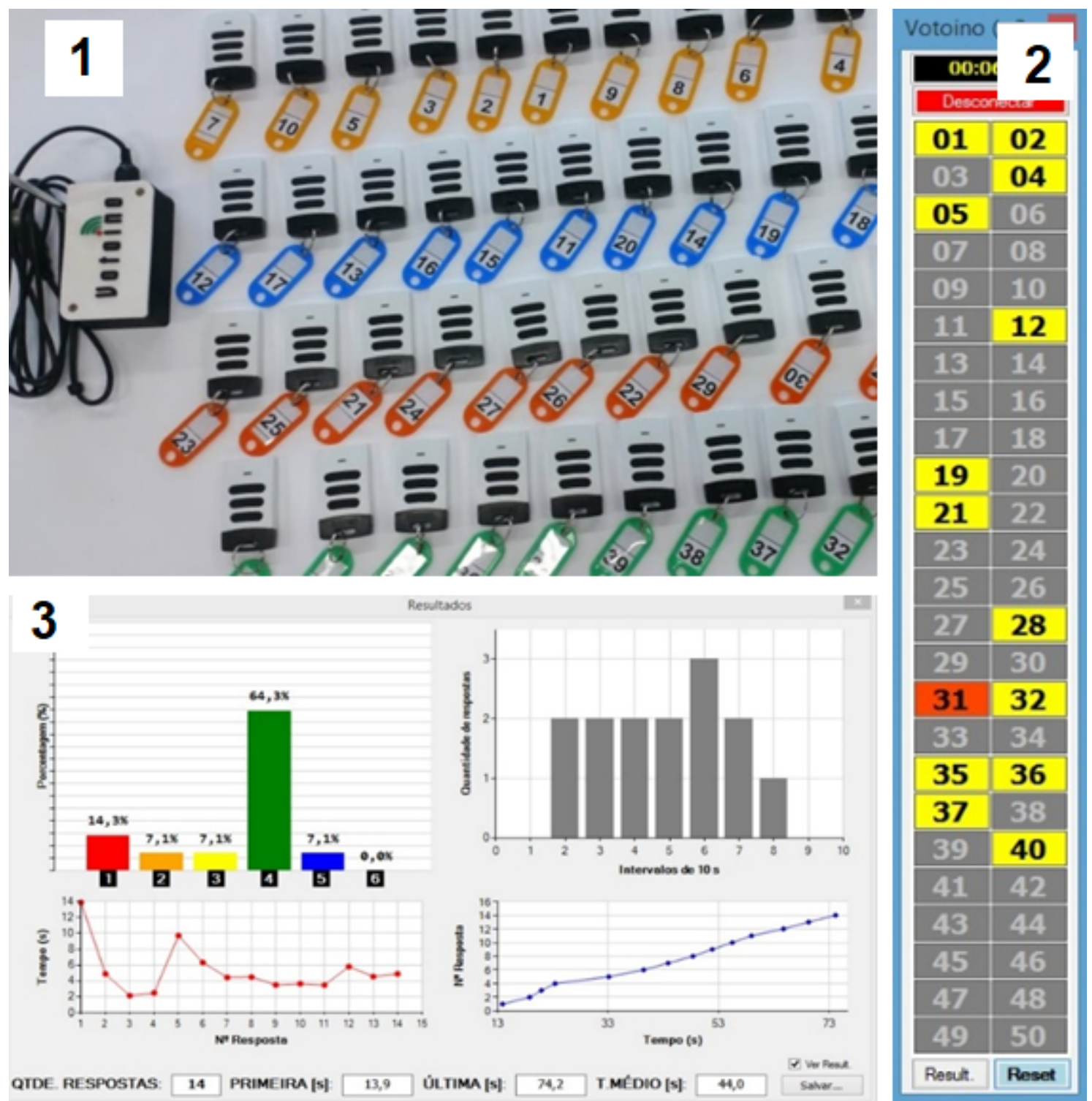

Fonte: próprio autor.

Para testar a eficiência da segunda versão do Votoino, aplicamos o dispositivo em uma aula de química que foi realizada no Instituto Federal de Educação, Ciência e Tecnologia de São Paulo (IFSP) campus Sertãozinho, em uma turma de $2^{\circ}$ ano do curso técnico integrado em automação industrial, no $3^{\circ}$ bimestre do ano de 2018. A turma era constituída por 39 alunos com idades entre 15 e 17 anos. O curso técnico integrado em automação industrial tem duração 
de 4 anos, sendo que a disciplina de química está inserida no curso com duas aulas semanais apenas no $1^{\circ}$ e $2^{\circ}$ anos, ou seja, trata-se de uma carga horária de química relativamente baixa para este nível de ensino.

Neste momento da disciplina o tema abordado é a Termoquímica. Foi planejada uma aula com duração de 1h30min, cujo tema principal foi "energia e os fenômenos endotérmicos e exotérmicos", com a seguinte sequência didática: discussão a partir do tema gerador "De onde vem a energia que usamos diariamente?"; breve exposição do conteúdo sobre fenômenos físicos e químicos diversos e sua classificação termoquímica, bem como as representações textuais e gráficas; e a resolução de exercícios ou testes conceituais (TCs) com o uso do sistema de votação eletrônica Votoino. Para trabalhar com o Votoino foram selecionados exercícios de vestibulares que foram usados integralmente ou adaptados.

No início da aula, o professor conecta o cabo USB da placa receptora do Votoino no notebook, distribui aleatoriamente os controles remotos entre os alunos, projeta o painel da figura 3.2 e pede que todos os alunos testem o funcionamento dos controles. Quando os alunos 'votam', o número do controle remoto no painel que fica projetado para a sala (sem atrapalhar ou se sobrepor aos slides projetados para a aula) muda de cinza para a amarelo, e apenas o aluno sabe qual o número do seu controle foi usado. A votação é totalmente anônima para incentivar a participação de todos.

A cada votação, os dados obtidos das respostas dos alunos dos TCs durante a aula eram armazenados no computador de modo automático e tratados de duas maneiras: imediatamente ao final do TC durante a aula, quando o professor projeta o resultado da votação no painel de resultados (figura 3.3) e realiza a próxima ação baseado neste resultado; e a partir da análise mais detalhada destes dados, salvos no computador, durante o planejamento da aula seguinte.

A respeito da metodologia da análise de dados, a princípio a pesquisa se pauta na análise qualitativa do uso do Votoino. Baseado em uma interpretação a partir da imersão no ambiente da sala de aula, buscamos entender a partir dos dados coletados o fenômeno da proposta da aula e seus impactos naquele contexto (durante a aula, uma aluna de iniciação científica fazia transcrições subjetivas sobre o comportamento dos alunos enquanto usaram o Votoino). Inicialmente usaremos a perspectiva do estudo de caso, baseando-se em Yin (2001) para tentar entender o "como" e "por quê" dos resultados obtidos. 


\section{RESULTADOS E DISCUSSÃO}

O conteúdo de Termoquímica no ensino médio é apresentado aos alunos quando se supõe que eles já tenham se familiarizado com a simbologia científica da química, bem como já tenham trabalhado com alguns conceitos e cálculos básicos que descrevem os fenômenos físicos e químicos de modo geral. O acompanhamento do desenvolvimento do aluno se torna essencial para que se possa diagnosticar o motivo pelo qual o aluno pode, ou não, obter sucesso no processo de aprendizagem deste tema. A partir do resumo da sequência das aulas apresentado na metodologia, nosso grupo apostou no monitoramento instantâneo da turma a partir do uso do Votoino. Buscou-se acompanhar se os alunos conseguiam, após a discussão do tema problematizador e da exposição curta do conteúdo, interpretar a linguagem do fenômeno e de sua energia envolvida em testes conceituais, variando os níveis de dificuldade entre os diferentes TCs ao longo da aula, e repensando a abordagem do tema a partir dos resultados das votações dos alunos.

É importante destacar que esta turma de $2^{\circ}$ ano de um curso técnico em automação industrial integrado ao ensino médio, de forma geral, tratava-se de um grupo bastante ativo, mas de certa forma apresentando dificuldades em acompanhar períodos longos de exposição de conteúdo, dispersando em conversas paralelas e uso de celulares. $\mathrm{O}$ fato de as duas aulas de química serem as primeiras às segundas-feiras dificultava o início da aula. Além disso o professor percebeu desde cedo que os alunos tinham bastante dificuldade em conteúdos básicos de química do $1^{\circ}$ ano, tais como: linguagem simples de funções inorgânicas, leitura e escrita de reações químicas, estequiometria, etc. A área da química abordada ao longo do semestre foi físico-química. $\mathrm{O}$ tema da aula que será analisada é a termoquímica, cujos principais conceitos abordados se referem a variação de energia na forma de calor em fenômenos físico-químicos.

Inicialmente, realizamos uma discussão com os alunos sobre a temática 'energia' e, a partir de uma aula expositiva de 20 minutos, abordamos conceitos gerais de energia e suas principais fontes e definimos os termos "processo endotérmico" e "exotérmico" para fenômenos físicos e químicos. Em seguida, aplicamos 5 TCs para verificar a concepção dos alunos sobre estes temas e, ao mesmo tempo, usar a sequência de testes para complementar as dúvidas dos alunos.

No TC 1, representado na figura 4, buscamos analisar a concepção sobre a classificação de um fenômeno físico em endotérmico ou exotérmico, além de revisar os termos referentes as passagens de estado físico. A resposta correta foi escolhida por 53\% dos alunos, de modo que 
acertaram tanto a classificação termoquímica quanto relembraram o termo usado na descrição da mudança de estado físico; a segunda alternativa mais votada obteve um índice de $24 \%$, que contém a classificação termoquímica incorreta do fenômeno, mas escolhida provavelmente em função do termo ebulição que pode ser adequado a tal passagem de estado físico. Dentre as alternativas que apresentam a classificação termoquímica correta (transformação endotérmica), $53 \%$ escolheram a alternativa $d$ e $8 \%$ a alternativa $c$, totalizando $61 \%$. Ao exibir o TC 1 na lousa, os alunos levaram o tempo máximo de 2 minutos e o resultado foi projetado de forma instantânea no formato do gráfico apresentado na figura 4, propiciando ao professor um panorama rápido e eficiente da percepção da turma sobre este contexto. O professor explicou o TC 1 comentando as duas alternativas mais escolhidas pelos alunos e continuou com mais um teste, o TC 2, para verificar se os alunos seriam capazes de fazer a classificação correta de um outro fenômeno físico.

Figura 4. TC 1 e resultado das respostas dos alunos sobre a classificação de um fenômeno físico.

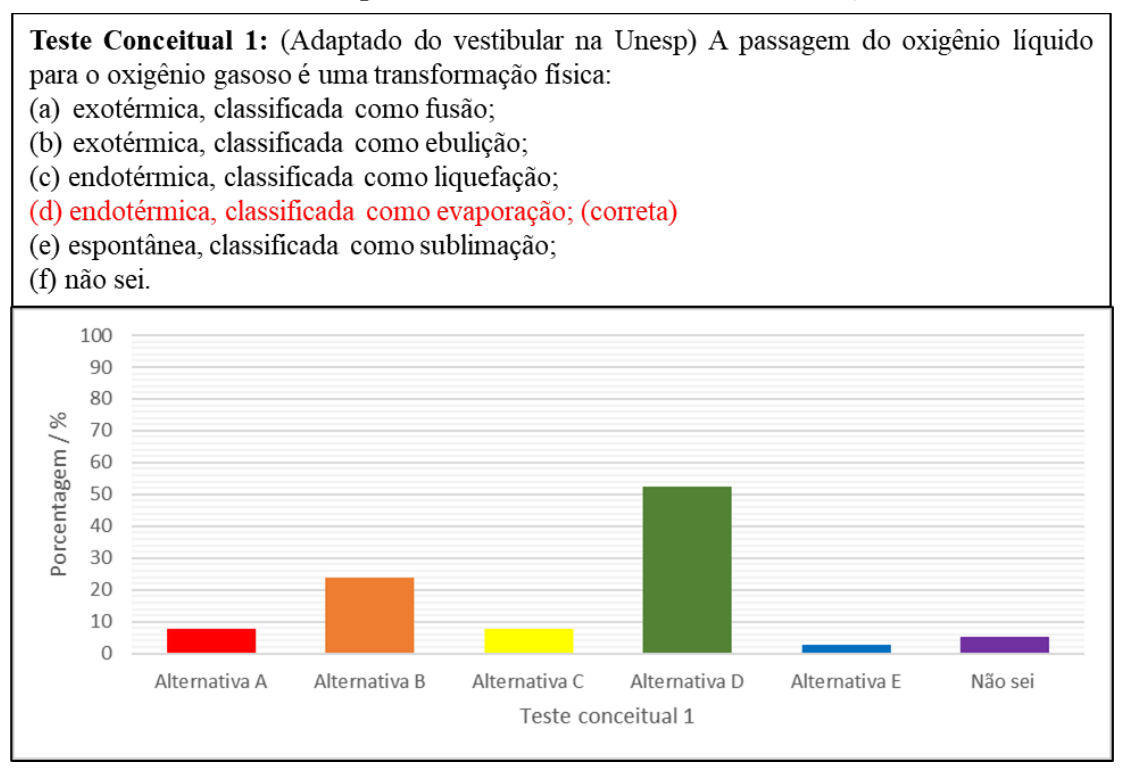

Fonte: Próprio autor.

No TC 2, representado na figura 5, perguntamos novamente sobre a classificação termoquímica de um fenômeno físico, agora em um contexto mais elaborado que exigia um pouco mais de atenção na interpretação dos alunos, mas mantendo o diagnóstico da percepção quanto ao fenômeno da mudança de estado físico. A maioria dos alunos escolheram a alternativa $b(66 \%)$, acertando a classificação do processo (transformação endotérmica) e a interpretação do texto quanto a fonte de calor necessária para a ocorrência do fenômeno. Outra 
parcela significativa (13\% - alternativa $a$ ) escolheu a alternativa que apresentava a classificação correta do fenômeno, somando assim, um total de $79 \%$ de acertos quanto a classificação termoquímica daquele fenômeno físico. Novamente o professor comentou o TC, tirando dúvidas de alguns alunos que resolveram participar da discussão.

Figura 5. TC 2 sobre a classificação de um fenômeno físico.

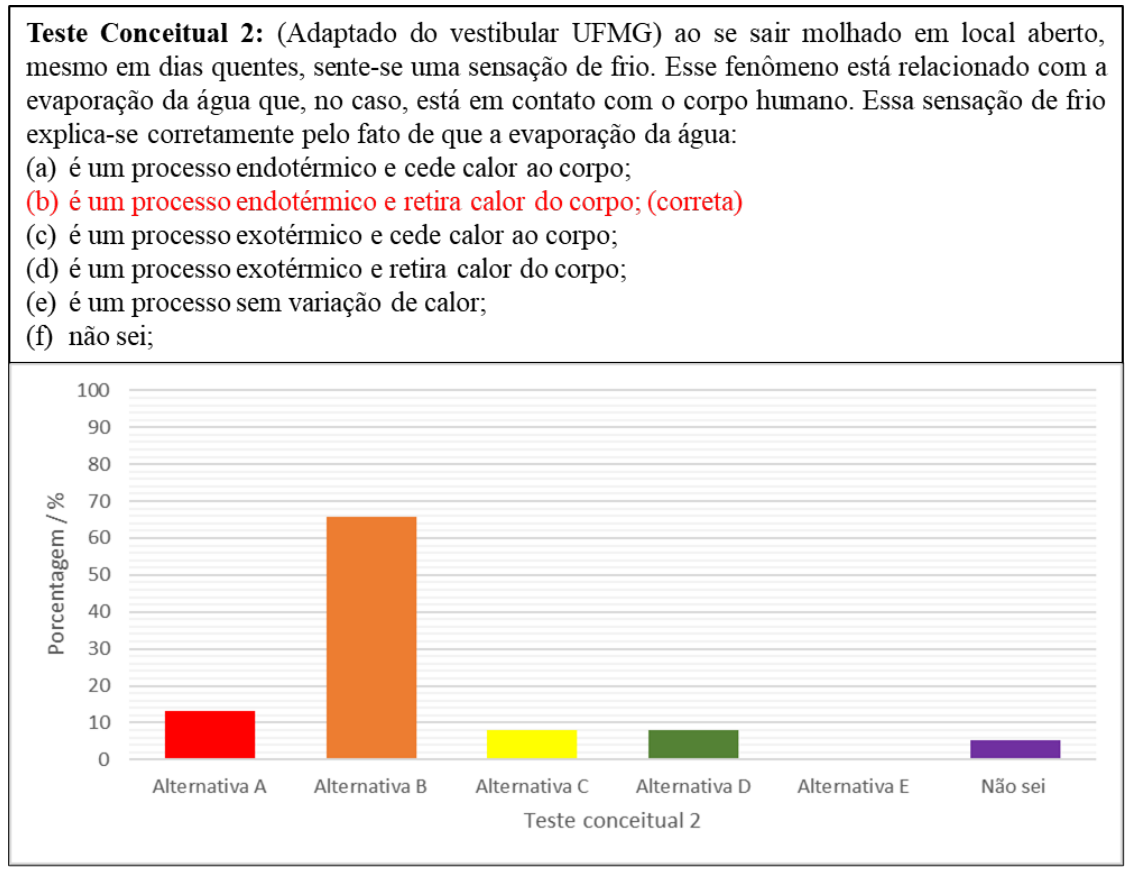

Fonte: Próprio autor.

No TC 3, perguntamos mais uma vez sobre processos endotérmico e exotérmico de forma genérica, iniciando o uso do aspecto quantitativo de transformações gerais e do termo 'entalpia', mantendo a ideia de diagnosticar um conceito que vem sendo elaborado ao longo dos testes e, ao mesmo tempo, refletir sobre elementos novos. O TC 3 teve um alto nível de acerto com índice de 90\%, apontando que os alunos fizeram um bom uso dos TCs para, naquele momento, melhorar a compreensão ou discernir a diferença entre os termos "endotérmico" e "exotérmico" em fenômenos físicos ou gerais. Se somarmos os alunos que acertaram o termo "endotérmico" respondendo alternativa $a$ ou $b$, o índice de acerto sobe para 95\%. Nota-se também que os alunos apresentaram boa desenvoltura com os dados quantitativos, embora sejam cálculos simples, aponta para uma boa introdução de exercícios mais complexos. Outro ponto importante e que gerava dúvidas em nosso grupo de pesquisa era a possibilidade de os alunos usarem o fato de que a votação é anônima para fazer mau uso do controle atrapalhando a ideia inicial do Votoino, porém a sequência de dados do TC1 ao TC3 mostram que os alunos, 
além de usarem o botão 6 para afirmar que não sabiam a resposta nos TCs 1 e 2, passaram a escolher uma alternativa no TC 3, o que pode demonstrar que a sequência dos exercícios teve algum resultado sobre o desenvolvimento da turma como um todo.

Figura 6. TC 3 sobre a classificação termoquímica.

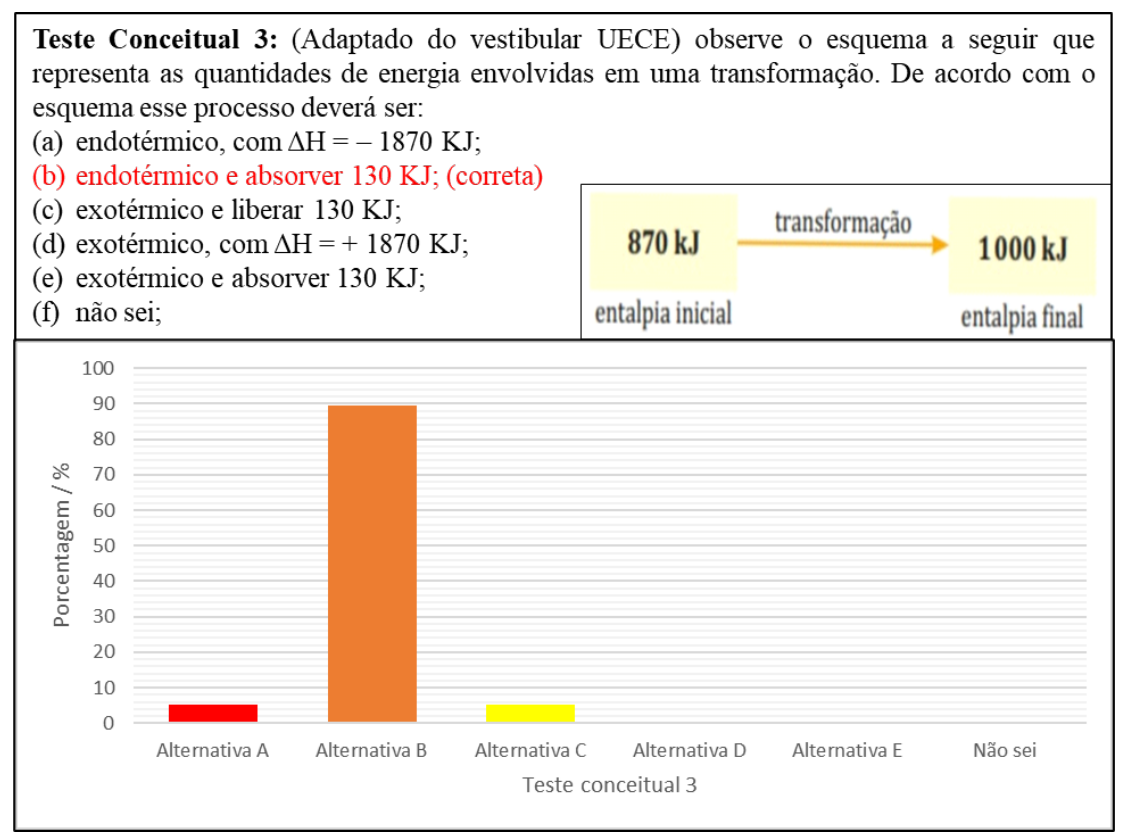

Fonte: Próprio autor.

Quando adicionamos uma transformação química, como no TC 4 (figura 7), observamos que o índice de acertos no TC diminuiu (60\% escolheram a alternativa correta e acertaram as duas classificações do TC), mas $87 \%$ acertaram a classificação da transformação química (quando somados $27 \%$ da alternativa $a$ e $60 \%$ da alternativa $b$ ), o que representa um bom índice. No entanto, o fato de $40 \%$ descrever a ebulição da água como um processo exotérmico é emblemático, uma vez que aparentemente nos TCs anteriores os alunos vinham aumentando seus índices de acertos. Este índice pode estar atrelado a questão da linguagem descritiva dos fenômenos e da percepção e interpretação dos alunos sobre os mesmos no cotidiano. Durante a discussão do TC 4, um dos alunos que participou da discussão afirmou que classificou o processo de ebulição da água como exotérmico porque a água em ebulição libera muita energia ou calor, o que causa alguns acidentes na cozinha, cabendo ao professor levar a discussão sobre a fonte deste calor da água 'quente'. 
Figura 7. TC 4 sobre a classificação termoquímica de fenômenos físico e químico.

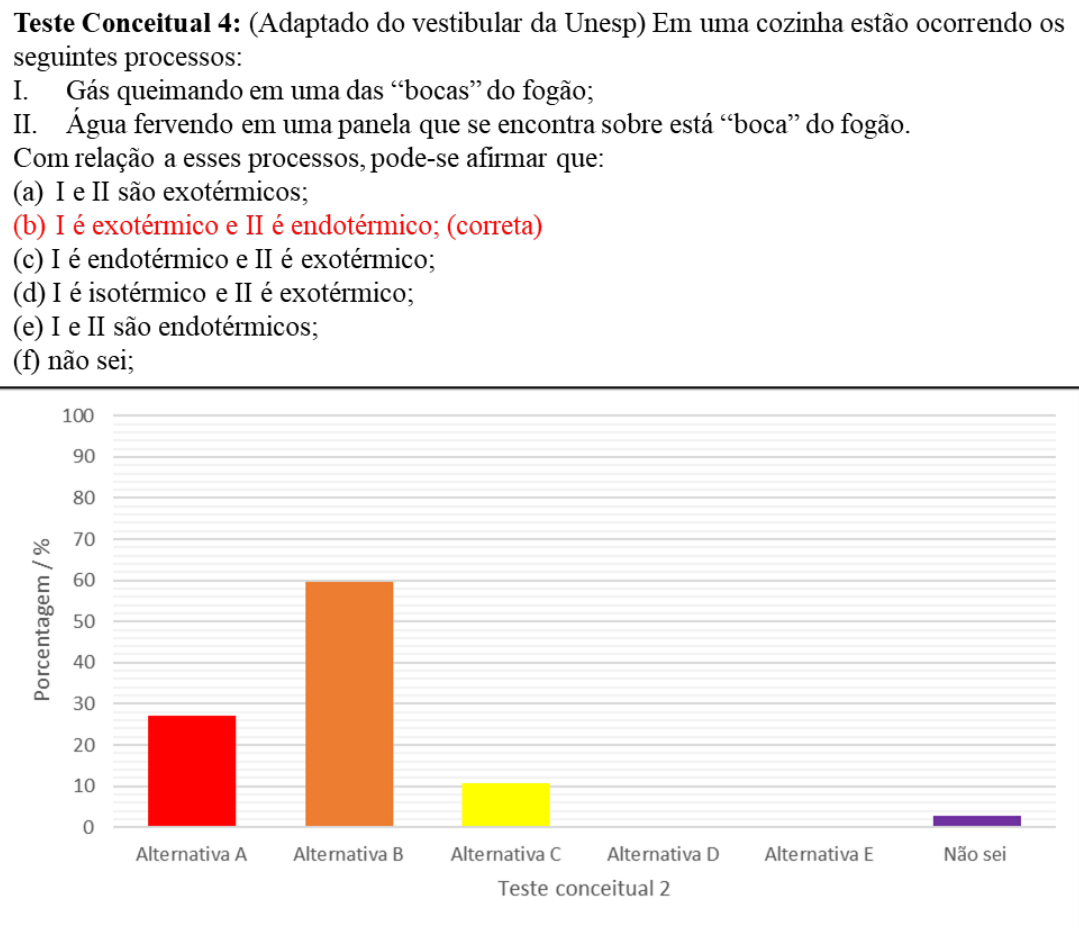

Fonte: Próprio autor.

Após a discussão do TC 4 pelo professor, os alunos responderam o TC 5 que envolvia a linguagem termoquímica da representação de reações químicas endotérmicas e exotérmicas através do $\Delta \mathrm{H}$, positivo ou negativo. Esse exercício possui maior texto e maior quantidade de reações a serem analisadas entre os 4 TCs anteriores. A maioria votou corretamente $(81 \%)$, o que novamente mostrou-se um bom índice de acertos, $10 \%$ dos alunos escolheram a alternativa $b$, provavelmente pela troca dos termos, e apenas 5\% usaram o botão 6 do controle remoto para se abster da resposta. A aula foi encerrada após a discussão do TC 5. 
Figura 8. TC 5 sobre a classificação termoquímica de reações químicas.

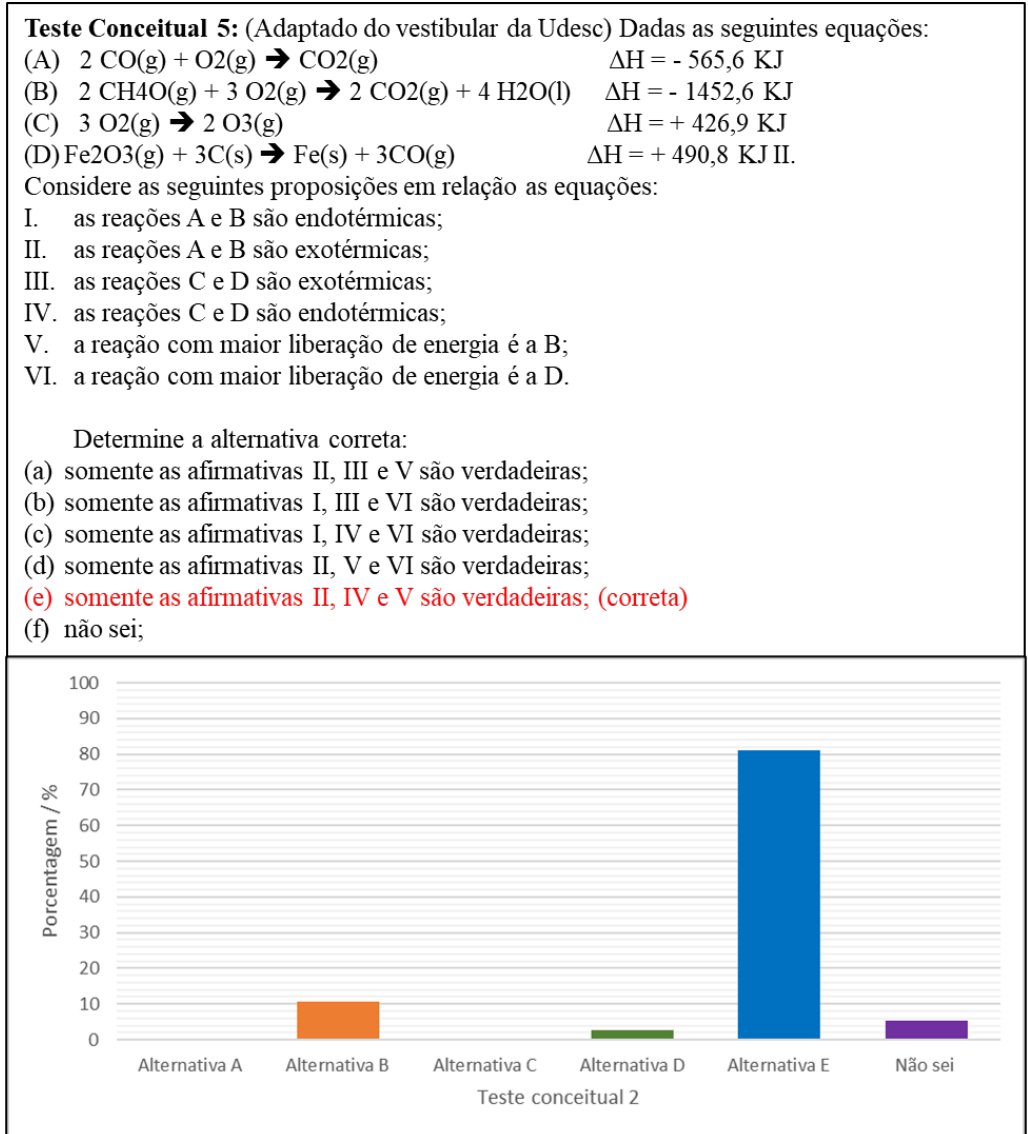

Fonte: Próprio autor

De imediato percebeu-se o quanto o Votoino mudou qualitativamente o comportamento dos alunos. Podemos apontar alguns fatores que influenciaram tal mudança: a surpresa com o dispositivo; a necessidade de participação de todos; a interação do aluno com o professor e com a sala como um todo de forma instantânea através do painel de votação; possibilidade de poder participar inclusive informando ao professor que não entendeu nada daquela aula, sem se expor. Tudo isso transformou, ao menos naquela aula, uma turma geralmente bastante dispersa em uma turma mais atenta. $\mathrm{O}$ uso do Votoino também trouxe um impacto imediato para o professor, pois os dados projetados na tela ao final de cada TC é um reflexo tanto da aprendizagem dos alunos quanto da didática do professor. De certa forma, há uma avaliação também instantânea da prática docente, com os resultados revelando muitas vezes um diagnóstico inesperado e exigindo um planejamento mais intenso das aulas. Novos direcionamentos na prática do professor durante a aula foram oferecidos pelos resultados dos TCs, o que possibilita a caracterização desse processo como uma avaliação formativa da turma.

Em reunião com o grupo de pesquisa, verificamos que, após a aula, os índices de acertos nos TCs (figura 9) mostram um crescimento do número de acertos do TC1 ao TC3 que 
abordaram a classificação termoquímica de fenômenos físicos. Observamos a queda do número de acertos do TC3 para o TC4 muito provavelmente porque foi inserido no TC4 duas transformações simultâneas, uma física e outra química, além de novos elementos de interpretação. Entre o TC 4 e o TC 5, houve novamente uma melhora nos resultados ainda que este último TC tenha uma linguagem mais elaborada e seja um exercício mais longo.

Figura 9. Comparação do índice de acertos de cada TC aplicado durante a aula.

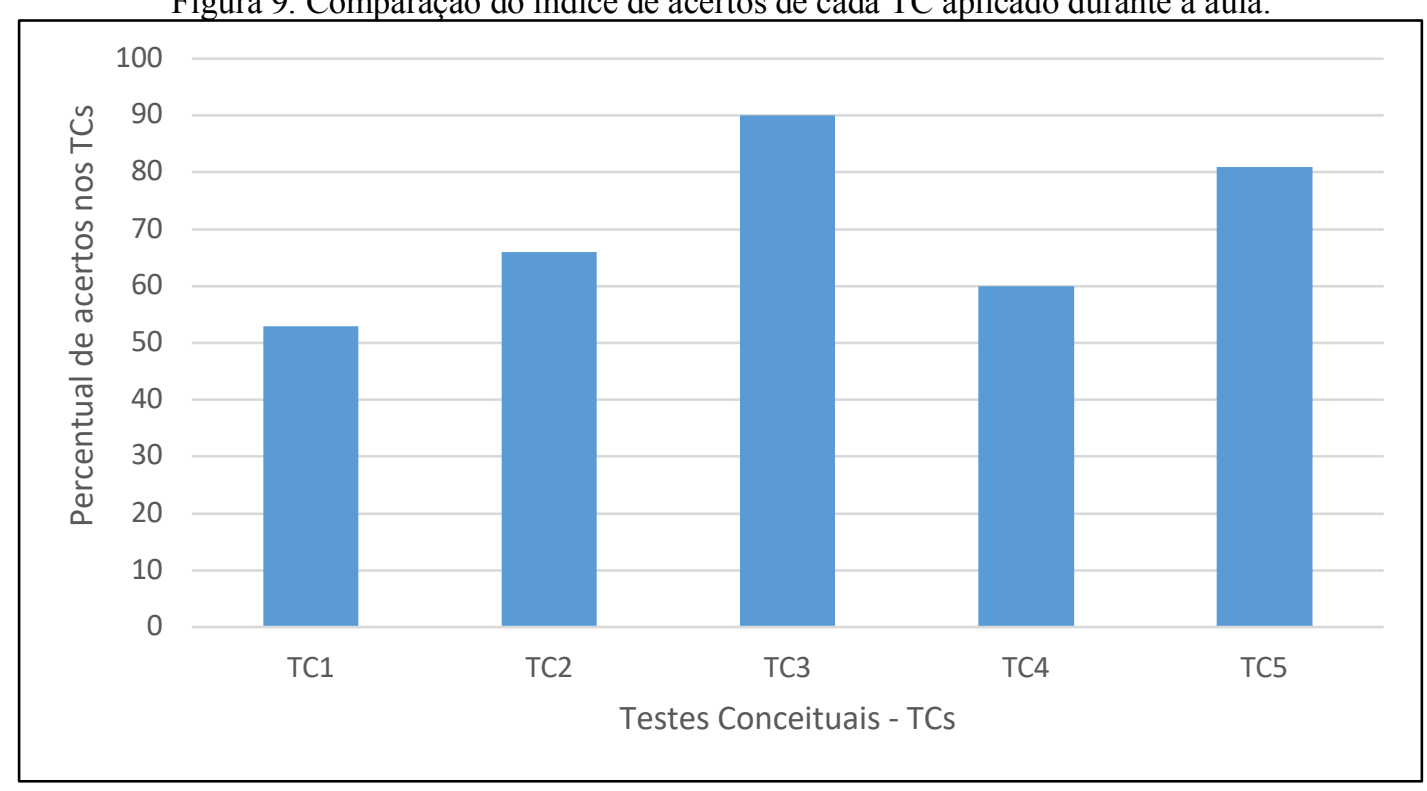

Fonte: próprio autor.

Nota-se que os TCs em sequência considerando diferentes níveis de dificuldade, se bem planejados, podem auxiliar na melhoria da compreensão de um conceito sendo, neste caso, a classificação e a linguagem de transformações que envolvem variação de energia. No entanto, deve-se ter cuidado com o tempo pois, muito embora o maior número de exercícios auxilie na compreensão, estes podem tomar bastante tempo de uma aula. Nesta aula, o número de 5 TCs apresentou-se de forma adequada para que todas as etapas da aula planejadas pelo professor, com duração de 1 h30min, fossem executadas.

\section{CONSIDERAÇÕES FINAIS}

O uso do clicker Votoino como uma ferramenta de avalição formativa na sala de aula mostrou-se bastante relevante, adequado e, particularmente, viável. Os resultados instantâneos - sem a necessidade de internet, celulares, tablets ou computadores - obtidos por um dispositivo eletrônico simples e que não atrapalha a dinâmica da aula, trouxe impactos positivos no comportamento dos alunos e na adequação e/ou novos direcionamentos da prática docente no 
curto espaço de uma aula. Os resultados da aplicação mostram a necessidade da escolha de testes conceituais adequados e alinhados com os objetivos da aula, bem como o planejamento prévio de diversas situações de sala de aula, antecipando-se às várias possibilidades de resultados insatisfatórios diagnosticados. O uso do Votoino de forma anônima pelo aluno, bem como a inserção do botão para que o aluno possa expressar que não entendeu o conteúdo, trouxe aspectos positivos para uma relação de maior confiança entre aluno e professor. Por fim, a compilação de dados de uma aula (dados automaticamente armazenados pelo software do Votoino) mostra informações muito interessantes sobre a evolução da turma (figura 9) durante a sequência didática, bem como levou o professor a replanejar a próxima aula, realizando a revisão da linguagem dos TCs e do nível de dificuldade dos mesmos.

\section{REFERÊNCIAS}

ARAUJO, A. V. R. de et al. Uma associação do método Peer Instruction com circuitos elétricos em contextos de aprendizagem ativa. Revista Brasileira de Ensino de Física, v. 39, n. 2, 2017. Disponível em: https://doi.org/10.1590/1806-9126-rbef-2016-0184

ARAUJO, I. S.; MAZUR, E. Instrução pelos colegas e ensino sob medida: uma proposta para o engajamento dos alunos no processo de ensino-aprendizagem de Física. Caderno

Brasileiro de Ensino de Física, v. 30, n. 2, 2013. Disponível em: https://doi.org/10.5007/2175-7941.2013v30n2p362

ASSUMPÇÃO, A. L. M.; SOARES, A. dos S. Metodologias Ativas - Pontos e Contrapontos de uma Proposta Metodológica. Revista Eixo, Brasília, v. 6, n. 1, janeiro- junho, p. 32-36, 2017. Disponível em:

http://revistaeixo.ifb.edu.br/index.php/RevistaEixo/article/view/403/241

BARBERIA, L. G. et al. Inovação no ensino de métodos quantitativos em Cîencia Poĺtica: Aplicação de modelo baseado em atividades. Agenda Poĺtica, v. 2, n. 2, p. 152-179, 2014. Disponível em: https://www.agendapolitica.ufscar.brindex.php/agendapolitica/article/view/48

CAMPAGNOLO, R. et al. Uso da abordagem Peer Instruction como metodologia ativa de aprendizagem: um relato de experiência. Signos, n. 2, p. 79-87, 2014. Disponível em: http://www.univates.br/revistas/index.php/signos/article/view/775

COSTA, R. G. da; PASSERINO, L. M.; ZARO, M. A. Fundamentos teóricos do processo de formação de conceitos e suas implicações para o ensino e aprendizagem de química. Ensaio Pesquisa em Educação em Ciências, Belo Horizonte, v. 14, n. 1, p. 271-281, 2012. Disponível em: https://doi.org/10.1590/1983-21172012140118

DIESEL, A. et al. Um olhar sobre uma proposta de formação inicial de professores voltada para as estratégias de leitura. Interfaces da Educação, Paranaíba, v. 3, n. 7, p. 37-48, 2017. 
Disponível em: https://doi.org/10.26514/inter.v1i3.628

DIESEL, A.; FORNECK, K. L.; MARTINS, S. N. Peer Instruction Na Formação Inicial De Professores: Uma Experiência Com O Uso Do Aplicativo Socrative. Revista Tecnologias na Educação, n. 14, p. 0-11, 2016. Disponível em: http://tecedu.pro.br/wpcontent/uploads/2016/07/Rel3-vol14-jul2016-Peer-instruction-na-formação-inicial-deprofessores-Uma-experiência-com-o-uso-do-aplicativo-socrative.pdf

DUMONT, L. M. M.; CARVALHO, R. S.; NEVES, A. J. M. O Peer Instruction Como Proposta De Metodologia Ativa no Ensino de Química. Journal of Chemical Engineering and Chemistry, v. 02, n. 2446-9416, p. 107-131, 2016. Disponível em: https://doi.org/doi: https://doi.org/10.18540/2446941602032016107 O

GAYDECZKA, B.; KARWOSKI, A. M. Pedagogia dos multiletramentos e desafios para uso das novas tecnologias digitais em sala de aula no ensino de língua portuguesa. Revista Linguagem \& Ensino, Pelotas, v. 18, n. 1, p. 151-174, 2015. Disponível em: https://periodicos.ufpel.edu.br/ojs2/index.php/rle/article/viewFile/15301/9489

KARWOSKI, A. M. A qualidade do ensino na educação superior. Revista Triângulo, v. 5, n. 2, 2013. Disponível em: https://doi.org/10.18554/rt.v5i1.374

KENSKI, V. M. Educação e Tecnologias: o novo ritmo da informação. 8. ed. Campinas: Papirus, 2012.

KIELT, E. D.; DA SILVA, S. de C. R.; MIQUELIN, A. F. Implementação de um aplicativo para smartphones como sistema de votação em aulas de Física com Peer Instruction. Revista Brasileira de Ensino de Fisica, v. 39, n. 4, 2017. Disponível em: https://doi.org/10.1590/1806-9126-RBEF-2017-0091

LIMA, B. S.; SANTOS, C. A. M. Peer-Instruction Usando Ferramentas On-line. Revista de Graduação USP, v. 1, n. 1, p. 83-90, 2016. Disponível em: http://www.revistas.usp.br/gradmais/article/view/117731

LIMA, J. I. de; TURCATO, A. C.; SILVA, F. de A. Uso do Votoino em Aulas de Química : usando a tecnologia como facilitadora da avaliação formativa em sala de aula. Revista EducaOnline, v. 14, n. 2, p. 67-89, 2020. Disponível em: http://www.latec.ufrj.br/revistas/index.php?journal=educaonline\&page=article\&op=view\&pat $\mathrm{h} \% 5 \mathrm{~B} \% 5 \mathrm{D}=1096$

LUCKESI, C. C. Avaliação da Aprendizagem: componente do ato pedagógico. São Paulo: Cortez, 2011.

MEDEIROS, R. A. C.; BESSA, A. MiniTeste: uma ferramenta ágil para aplicação de avaliações personalizadas. Revista Novas Tecnologias na Educação, v. 15, n. 1, p. 1-10, 2017. Disponível em: https://doi.org/10.22456/1679-1916.75126

MORAN, J. M. A Educação que Desejamos: novos desafios e como chegar lá. $5^{\mathrm{a}}$ ed. Campinas: Papirus, 2012. 
MÜLLER, M. G. et al. Implementação do método de ensino Peer Instruction com o auxílio dos computadores do projeto "UCA" em aulas de Física do Ensino Médio. Caderno Brasileiro de Ensino de Física, v. 29, n. 0, p. 491-524, 2012. Disponível em: https://doi.org/10.5007/2175-7941.2012v29nesp1p491

MÜLLER, M. G. et al. Uma revisão da literatura acerca da implementação da metodologia interativa de ensino Peer Instruction (1991 a 2015). Revista Brasileira de Ensino de Física, v. 39, n. 3, 2017. Disponível em: https://doi.org/10.1590/1806-9126-rbef-2017-0012

MÜLLER, M. G.; ARAUJO, I. S.; VEIT, E. A. Metodologias interativas de ensino na formação de professores de física: um estudo de caso com o método instrução pelos colegas (Peer Instruction). Alexandria: Revista de Educação em Ciência e Tecnologia, v. 10, n. 2, p. 171, 2017. Disponível em: https://doi.org/10.5007/1982-5153.2017v10n2p171

OLIVEIRA, E. A. de. Uso de questionários no Moodle como apoio para aprendizagem. Revista de Graduação USP, v. 2, n. 3, p. 175, 2017. Disponível em: https://doi.org/10.11606/issn.2525-376x.v2i3p175-178

OLIVEIRA, T. E. de; ARAUJO, I. S.; VEIT, E. A. Aprendizagem Baseada em Equipes (Team-Based Learning): um método ativo para o Ensino de Física. Caderno Brasileiro de Ensino de Física, v. 33, n. 3, p. 962, 2016. Disponível em: https://doi.org/10.5007/21757941.2016v33n3p962

OLIVEIRA, M. A. F. et al. Aplicação do método Peer Instruction no ensino de Algoritmos e programação de computadores. Revista Novas Tecnologias na Educação, v. 15, n. 1, p. 111, 2017. Disponível em: https://doi.org/10.22456/1679-1916.75141

OLIVEIRA, V.; VEIT, E. A.; ARAUJO, I. S. Relato de experiência com os métodos Ensino sob Medida (Just-in-Time Teaching) e Instrução pelos Colegas (Peer Instruction) para o Ensino de Tópicos de Eletromagnetismo no nível médio. Caderno Brasileiro de Ensino de Física, v. 32, n. 1, p. 180, 2015. Disponível em: https://doi.org/10.5007/2175$7941.2015 \mathrm{v} 32 \mathrm{n} 1 \mathrm{p} 180$

PASQUALETTO, T. I.; VEIT, E. A.; ARAUJO, I. S. Aprendizagem Baseada em Projetos no Ensino de Física: uma Revisão da Literatura. Revista Brasileira de Pesquisa em Educação em Ciências, v. 17, n. 2, p. 551-577, 2017. Disponível em: https://doi.org/10.28976/19842686rbpec2017172551

PERRENOUD, P. Avaliação: da excelência à regulação das aprendizagens. Porto Alegre: Artmed, 1999.

REIS, A. F. M. V.; BARRETO, M. A. M. Uma experiência com Think Pair Share no Ensino Fundamental I. Revista Práxis, v. 9, n. 17, 2017. Disponível em:

http://revistas.unifoa.edu.br/index.php/praxis/article/view/797

RIBEIRO, J. B. P. et al. Intervenção Pedagógica E Metodologia Ativa: O Uso Da Instrução Por Colegas Na Educação Profissional. Periódico Científico Outras Palavras, v. 12, n. 2, p. 
1-16, 2016. Disponível em:

http://revista.faculdadeprojecao.edu.br/index.php/Projecao5/article/view/715

RIBEIRO, M. E. M.; RAMOS, M. G. Grupos Colaborativos como Estratégia de Aprendizagem em Aulas de Química. Acta Scientiae, Canoas, v. 14, n. 3, p. 456-471, 2012. Disponível em: http://www.periodicos.ulbra.br/index.php/acta/article/view/394

SILVA LEITE, B. Gamificando as aulas de química: uma análise prospectiva das propostas de licenciandos em química. Revista Novas Tecnologias na Educação, v. 15, n. 2, 2018. Disponível em: https://doi.org/10.22456/1679-1916.79259

TEIXEIRA, K. C. B.; FONTENELE, F. C. F. Metodologia Peer Instruction no ensino de matrizes: um relato de experiência na disciplina de álgebra linear. Educação Matemática em Revista, v. 1, n. 18, p. 57-65, 2017.

YIN, R. K. Estudo de caso: planejamento e métodos, 2. ed. Porto Alegre, Bookman, 2001. ZANATTA, S. C. et al. Peer Instruction: discussões que permeiam a formação reflexiva e o ensino de ciências. Revista de Produtos Educacionais e Pesquisas em Ensino, v. 1, n. 1, p. 157-178, 2017. Disponível em: http://seer.uenp.edu.br/index.php/reppe/article/view/1114 